\begin{tabular}{|c|c|c|}
\hline $\mathrm{CaM}$ & $\begin{array}{l}\text { Construction and Material Journal } \\
\text { e-ISSN 2655-9625, http://jurnal.pnj.ac.id/index.php/cmi }\end{array}$ & $\begin{array}{l}\text { Volume } 3 \text { No. } 2 \\
\text { Juli } 2021\end{array}$ \\
\hline
\end{tabular}

\title{
ANALISIS SIFAT FISIS AGREGAT HALUS PASIR DAN LIMBAH PLASTIK
}

\author{
Muhtarom Riyadi $\bowtie \mathbf{1}$, Tri Wulan Sari ${ }^{2}$ \\ ${ }^{1}$ Jurusan Teknik Sipil, Politeknik Negeri Jakarta, JL. Prof DR. G.A. Siwabessy, Kampus Universitas \\ Indonesia, Depok, 16425 \\ muhtarom@sipil.pnj.ac.id ${ }^{\square 1}$, tri.wulansari@sipil.pnj.ac.id四2
}

\begin{abstract}
Based on SNI 03-2847-2002, concrete can be defined as a mixture of cement, fine aggregate, coarse aggregate, water, and with or without other additives. The purpose of this study was to analyze the physical properties of fine aggregate sand and plastic waste such as SSD specific gravity, SSD specific gravity, bulk density, sieve analysis, moisture content, and sludge content. According to the Indonesian National Standard (SNI), the method used is the observation method by conducting direct testing in the laboratory. The results obtained indicate that the study of fine aggregate sand by testing SSD bulk specific gravity, bulk density, sieve analysis, moisture content, and silt content meet the standard specifications for making concrete. At the same time, the research conducted on the fine aggregate of plastic waste did not meet the specifications.
\end{abstract}

Keywords: Aggregate; Physical Properties; sand; plastic waste.

\begin{abstract}
ABSTRAK
Beton menurut salah satu sumber yaitu SNI 2847:2013 dapat memiliki arti campuran semen Portland atau semen hidrolisis yang lain, agregat halus, agregat kasar, dan air, dengan atau tanpa bahan campuran tambahan (mixture). Tujuan dari penelitian ini adalah menganalisis sifat fisis dari agregat halus pasir dan limbah plastic seperti berat jenis SSD, berat jenis SSD, berat isi, Analisa ayak, kadar air, dan kadar lumpur. Metode yang dilakukan adalah menggunakan metode observasi dengan cara melakukan pengujian langsung di laboratorium sesuai Standar Nasional Indonesia (SNI). Hasil yang diperoleh menunjukkan bahwa pada penelitian agregat halus pasir dengan pengujian berat jenis SSD sebesar 2,55; penyerapan air sebesar 2,35\%; berat isi / massa jenis lepas sebesar 1,33 Kg/liter; berat isi / massa jenis padat sebesar 1,56 Kg/liter; analisa ayak sebesar 2,90; kadar air sebesar 1,93\%; dan kadar lumpur sebesar 3\%. Nilai tersebut memenuhi standar spesifikasi pembuatan beton berdasarkan SNI 1969:2008. Sedangkan penelitian yang dilakukan terhadap agregat halus limbah plastik tidak memenuhi spesifikasi dan dapat dilihat pada pembahasan maupun lampiran.
\end{abstract}

Kata Kunci : Agregat; Sifat fisis; pasir; limbah plastik.

\section{PENDAHULUAN}

Infrastruktur pada era milenial ini telah mengalami kemajuan pesat, misalnya pada pembangunan infrastruktur, gedung bertingkat yang tinggi, dan fasilitas lainnya [1], [2]. Campuran semen Portland atau semen hidrolisis yang lain, agregat halus, agregat kasar, dan air, dengan atau tanpa bahan campuran tambahan (mixture) berdasarkan SNI 03-2847-2002 dan SNI 2847:2013 disebut beton [3], [4].
Berdasarkan data dari Balitbang Kimpraswil (2003b), beton ringan merupakan beton yang memakai agregat ringan maupun campuran agregat kasar ringan dan pasir alami yang juga dapat digunakan sebagai pengganti agregat halus ringan dengan ketentuan tidak boleh melampaui berat isi/volume atau massa jenis maksimum beton yaitu sebesar $1850 \mathrm{~kg} / \mathrm{m} 3$ kering udara, yang diharuskan memenuhi ketentuan kuat tekan dan kuat tarik belah beton ringan untuk tujuan struktural [5]. 
Agregat dapat diartikan sebagai salah satu bahan utama pembentuk beton selain pasta semen. Kadar agregat dalam campuran berkisar pada 60-80\% dari jumlah seluruh isi/volume beton. Oleh sebab itu, kualitas agregat dapat dikatakan berpengaruh terhadap kualitas beton dalam penelitian Nugroho 1983 [6]. Agregat yang digunakan untuk campuran beton dapat dibedakan menjadi dua jenis yaitu agregat halus dan agregat kasar [6]. Para peneliti hingga saat ini melakukan pengujian berbagai material alternatif untuk memenuhi kebutuhan pembangunan konstruksi [7]. Misalnya Penelitian yang dilakukan oleh Muhatorm dkk 2015 untuk mendapatkan material alternatif dengan cara mendapat-kan karakteristik agregat kasar buatan dari limbah kantong plastik jenis HDPE (High Density PolyEthylene) dalam mengurangi limbah kantong plastik jenis HDPE serta mengurangi pemakaian agregat kasar batu split pada beton sehingga eksploitasi batu split dapat berkurang [8]. Hasil Pemeriksaan Sifat-sifat Agregat Halus yang dilakukan oleh Musrifin dkk diperoleh hasil karakteristik agregat halus dan agregat kasar yang diperoleh dari Kawasan Kali Baubau ada yang masuk standar ada juga yang tidak termasuk standar pemeriksaan yang disyaratkan, misalnya absorbsi pasir sebesar 2,42\%; kadar lumpur pasir $3,10 \%$, kondisi lepas kerikil 1,45, dst [9].

Penambahan yang dilakukan dengan menggunakan cacahan gelas plastik polypropylene (PP) terhadap berat semen kedalam campuran beton dapat meningkatkan kuat tarik belah beton [10]. Agregat halus diuji untuk mengetahui sifat fisis jenis pengujian antara lain : pengujian kadar lumpur, kadar air agregat, berat jenis dan penyerapan, berat volume/isi [11].

Perhitungan sifat fisis dalam penelitian ini berdasarkan perhitungan berikut ini:

\section{a. Berat jenis Saturated Surface Dry (SSD)}

Perhitungan berat jenis curah jenuh kering permukaan/ Saturated Surface Dry (berat jenis SSD) pada temperatur air $23^{\circ} \mathrm{C}$ / temperatur agregat $23^{\circ} \mathrm{C}$ menggunakan rumus berikut ini:

$$
\text { Berat jenis } S S D=\frac{B}{(B-C)}
$$

Keterangan:

$\mathrm{B}=$ berat benda uji kondisi jenuh kering permukaan di udara (gram) $\mathrm{C}=$ berat benda uji dalam air (gram) [3].

Berat jenis SSD diperoleh dengan Berat kondisi SSD dibagi dengan Berat kondisi SSD + berat piknometer dan air - Berat kondisi SSD + berat piknometer dan air [12].

\section{b. Penyerapan Air}

Cara menghitung persentase penyerapan air $(\mathrm{Sw})$ dengan menggunakkan rumus

$$
\text { Penyerapan air }=\frac{B-A}{A} \times 100 \%
$$

Keterangan:

$\mathrm{A}=$ berat benda uji kering oven (gram)

$\mathrm{B}=$ berat benda uji kondisi jenuh kering permukaan di udara (gram) [3].

\section{c. Berat isi (Massa Jenis)}

Berat isi merupakan perbandingan antara berat beton dengan volume (isi) silinder sebagai alat pengukur volume.

Pengujian berat isi dilakukan berdasarkan SNI 03-1973-1990 [13]. Dengan menggunakan rumus sebagai berikut.

Dimana :

$$
\text { berat isi }=\frac{W}{V}
$$

Berat isi beton $\left(\mathrm{kg} / \mathrm{m}^{3}\right)$

$\mathrm{W}=$ berat beton $(\mathrm{kg})$

$\mathrm{V}=$ volume beton $\left(\mathrm{m}^{3}\right)$.

Berdasarkan penjabaran tersebut penelitian ini memiliki tujuan melakukan analisis sifat fisis agregat 
halus pasir dan limbah plastik dengan menggunakan metode observasi langsung di laboratorium.

\section{METODE PENELITIAN}

Metode pada penelitian ini yaitu metode observasi yang caranya dapat dilakukan dengan pengujian langsung di laboratorium sesuai Standar Nasional Indonesia (SNI) 2847:2013. Bahan agregat halus yang digunakan dalam penelitian ini adalah pasir yang ditunjukkan oleh Gambar 1 dan Gambar 2 menunjukkan agregat halus plastik limbah yang telah dihancurkan. Gambar 3 menunjukkan ukuran yang digunakan saat pengujian.

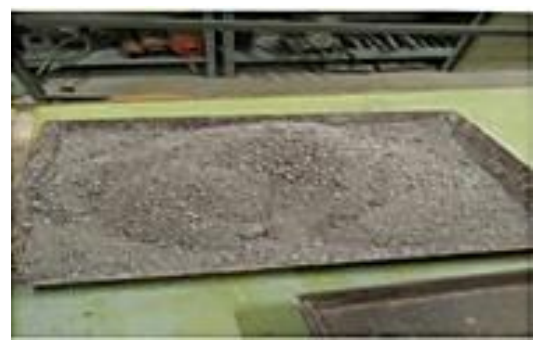

Gambar 1. Bahan Agregat halus Pasir

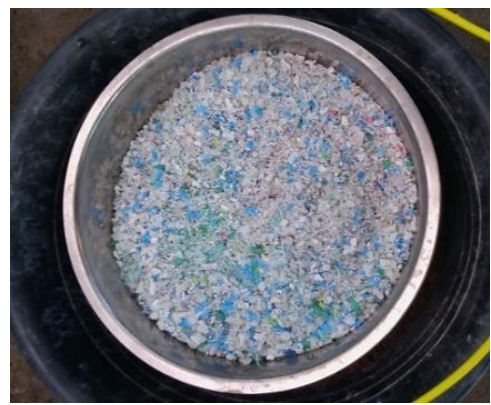

Gambar 2. Bahan agregat halus plastik limbah yang telah dihancurkan

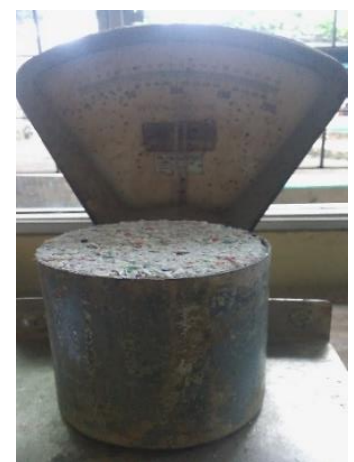

Gambar 3. Ukuran silinder yang dgunakan untuk pengujian agregat halus
Adapun langkah - langkah yang dilakukan dimulai dari mempersiapkan alat dan bahan, kemudian melakukan pengujian bahan dengan menggunakan agregat halus pasir dan limbah plastik. Pengujian terhadap agregat halus pasir dilakukan dengan mengukur berat jenis dan penyerapan air, berat isi, analisa ayak, kadar air, dan kadar lumpur. Sedangkan untuk pengujian agregat halus limbah plastik dilakukan dengan menguji berat jenis, berat isi, dan analisis ayak. Diagram alir metode penelitian dapat dilihat pada Gambar 4 pada lampiran.

\section{HASIL dan PEMBAHASAN}

\section{Agregat Halus (Pasir)}

Tabel 1 pada lampiran menunjukkan hasil penelitian Agregat halus pasir dan diperoleh hasil berat jenis SSD agregat halus (pasir) sebesar 2,55. Nilai tersebut memenuhi SNI 2847:2013 sebagai agregat normal berdasarkan berat jenis SSD-nya yaitu sebesar 2,0-2,9. Untuk sifat fisis penyerapan air diperoleh hasil penelitian sebesar $2.35 \%$, yang berarti bahwa kemampuan agregat dalam penyerapan air tidak melebihi syarat yang diizinkan yaitu 3\% menurut SNI 2847:2013. Sedangkan berat isi lepas rata-rata diperoleh sebesar $1,327 \mathrm{~kg} / \mathrm{liter}$ dan padat sebesar $1,56 \mathrm{~kg} / \mathrm{liter}$. Nilai voids pengujian berat isi lepas $35.54 \%$, dan voids berat isi padat $24.22 \%$. Nilai tersebut masih termasuk dalam batas teoritis yaitu maksimum $50 \%$.

Angka kehalusan pada penelitian ini diperoleh sebesar 2,90, dan memenuhi batas teoritis berdasarkan SI No. 52 tahun 1980 yaitu 1,5-3,8. Jika dilihat pada Gambar 5, agregat halus yang digunakan memenuhi spesifikasi di zona 2 (British Standard) [14].

Hasil penelitian kadar air didapatkan kadar air rata-rata sebesar 1,93\%. Hal ini terkait dengan pengujian penyerapan air 
agregat halus di atas adalah $2.35 \%$. Oleh karena itu, jika dilakukan pembuatan beton diperlukan penambahan sebesar $0.42 \%$. Hasil uji kadar lumpur pada agregat halus diperoleh rata-rata nilai kadar lumpur sebesar 3\%. Nilai ini dibawah batas yang disyaratkan yaitu maksimum 5\% sesuai dengan ASTM C117-95 [15] sehingga agregat halus ini dapat digunakan.

\section{Agregat Halus (Limbah Plastik)}

Tabel 1 pada lampiran juga menunjukkan hasil pengujian agregat halus limbah plastik. Hasil tersebut terlihat bahwa berat jenis pada agregat halus limbah plastik didapat berat jenis SSD sebesar 0,89 dan penyerapan air rata-rata $0 \%$. Hasil tersebut menunjukan bahwa agregat halus dari limbah plastik ini tidak dapat menyerap air. Selanjutnya, berat isi rata-rata yang didapat dengan cara dilepas sebesar 0.46 $\mathrm{kg} / \mathrm{liter}$ dan dipadatkan sebesar 0.55 $\mathrm{kg} /$ liter berdasarkan SII No.52 tahun 1980 tidak memenuhi yang diiznkan yaitu sebesar minimal minimal 1,2 $\mathrm{gr} / \mathrm{cm}^{3}$ [16] . Sedangkan nilai voids pengujian berat isi lepas $48.45 \%$, dan voids berat isi padat $38.77 \%$, nilai tersebut masih dalam batas teoritis yaitu maksimum 50\%. Analisis ayak didapat angka kehalusan sebesar 4,15. Agregat halus dari limbah plastik tidak memenuhi batas teoritis $1.50-3.8$ berdasarkan SII No.52 tahun 1980 [16] . Jika dilihat pada Gambar 6 hasil analisis ayak ini tidak memenuhi spesifikasi zona 2 (British Standar) [14].

\section{KESIMPULAN}

Berdasarkan hasil dan pembahasan dapat diambil kesimpulan bahwa pada penelitian agregat halus pasir dengan pengujian berat jenis SSD, berat isi, Analisa ayak, kadar air, dan kadar lumpur memenuhi standar spesifikasi pembuatan beton. Penelitian yang dilakukan terhadap agregat halus limbah plastik tidak memenuhi spesifikasi. Oleh karena itu, ke depannya perlu dilakukan penelitian lebih lanjut mengenai pencampuran limbah plastik sebagai salah satu bahan campuran beton.

\section{DAFTAR PUSTAKA}

[1] A. E. Bachtiar, S. Gusty, F. Rachim, R. dan A. Setiawan, "Pemanfaatan Daur Ulang Limbah Plastik Polyethylene Terephthalate (Pet) Sebagai Pengganti Agregat Kasar Pada Beton," Kacapuri, pp. 156-164, 2020.

[2] B. Soebandono, A. Pujianto dan D. Kurniawan, "Perilaku Kuat Tekan dan Kuat Tarik Beton Campuran Limbah Plastik HDPE," Jurnal Ilmiah Semesta Teknika, vol. 16, no. 1, pp. 76-82, 2013.

[3] B. S. Nasional, "Persyaratan Beton struktural untuk bangunan gedung". Indonesia Paten SNI 2847:2013, 2013.

[4] E. Modesta dan Z. , "Pengaruh Penggunaan Botol Plastik Polyethylene Terephthalate (PET) sebagai Tambahan Serat Terhadap Kekuatan Beton," dalam 6th ACE Conference, Padang, 2019.

[5] N. A. Jalali dan H. Halim, "Karakteristik Beton dengan Agregat Kasar Pellet Polypropylene Dan Variasi Agregat Halus," INERSIA, vol. X, no. 1, pp. 34-43, 2014.

[6] Husaini dan Mahdi, "Penggunaan Limbah Botol Plastik Sebagai Agregat Pada Campuran Beton Dengan Penambahan Silika Fume," Lentera, vol. 15 , no. 15 , pp. 109123, 2015.

[7] N. . A. Jalali, "Kuat Tekan Dan Modulus Elastisitas Beton Beragregat Kasar Pellet Plastik Polypropylene," dalam Seminar Nasional III Teknik Sipil 
Universitas Muhammadiyah

Surakarta, Surakarta, 2013.

[8] M. Riyadi, M. H. Rizkin dan . Z. , "Pemanfaatan Limbah Plastik Simpul Sebagai Pengganti Agregat Kasar Pada Beton," Politeknologi, vol. 14, no. 1, pp. -, 2015.

[9] M. S. Yahya dan C. T. Angka, "Analisis Sifat - Sifat Karkteristik Agregat dengan Menggunakan Agregat Kasar dan Halus di Kawasan Kali Baubau dengan Menggunakan Air Payau," SCEJ (Shell Civil Engineering Journal), vol. 3, no. 2, 2018.

[10] A. P. Firdaus dan J. , "Pengaruh Penggunaan Limbah Plastik Polypropylene (Pp) Sebagai Campuran Agregat Kasar Terhadap Kuat Tekan Dan Tarik Pada Beton FC' 25 MPA," J. Infras, vol. 3, no. 2, pp. 81-89.

[11] M. . A. Sultan, A. Tata dan A. Wanda, "Penggunaan Limbah Plastik PP Sebagai Bahan Pengikat pada Campuran Paving Block," sIKLUs: Jurnal Teknik Sipil, vol. 6, no. 2, pp. 95 - 102, 2020.

[12] N. M. Christina, "Bahan Bangunan Laut," Wordpress.com, 28 November 2018. [Online]. Available:

https://nadyameichristinakl17.wor dpress.com/2018/11/28/praktikumminggu-ke-2-berat-jenis-danpenyerapan-agregat/. [Diakses 10 Juli 2021].

[13] D. P. U. "SNI 03-1971-1990 . Metode Pengujian Kadar Air Agregat," Pekerjaan Umum, Jakarta, 1990.

[14] B. S. Institution, "Structural Use of Concrete -". Paten BS 88101:1997 Incorporating Amendments Nos. 1, 2, 3 and 4, 2012.

[15] ASTM C 29M-97, "Standard Test Method for Bulk Density (Unit Weight) and Voids in Aggregate,
ASTM International". 100 Barr Harbor Drive, United States 2003.

[16] M. S. Lamotokana, S. . I. Latuconsina dan S. Adek, "Studi Eksperimental Abu Vulkanik Sebagai Bahan Subtitusi Parsial Semen Terhadap Kuat Tekan Beton Normal," Dintek, vol. 13, no. 1, pp. 63-71, 2020.

[17] Universitas Islam Indonesia, [Online]. Available: https://dspace.uii.ac.id/bitstream/h andle/123456789/2844/05.6\%20ba b\%206.pdf?sequence $=10$ \&isAllow ed=y. [Diakses 10 Juli 2021]. 


\section{Lampiran Tabel dan Gambar}

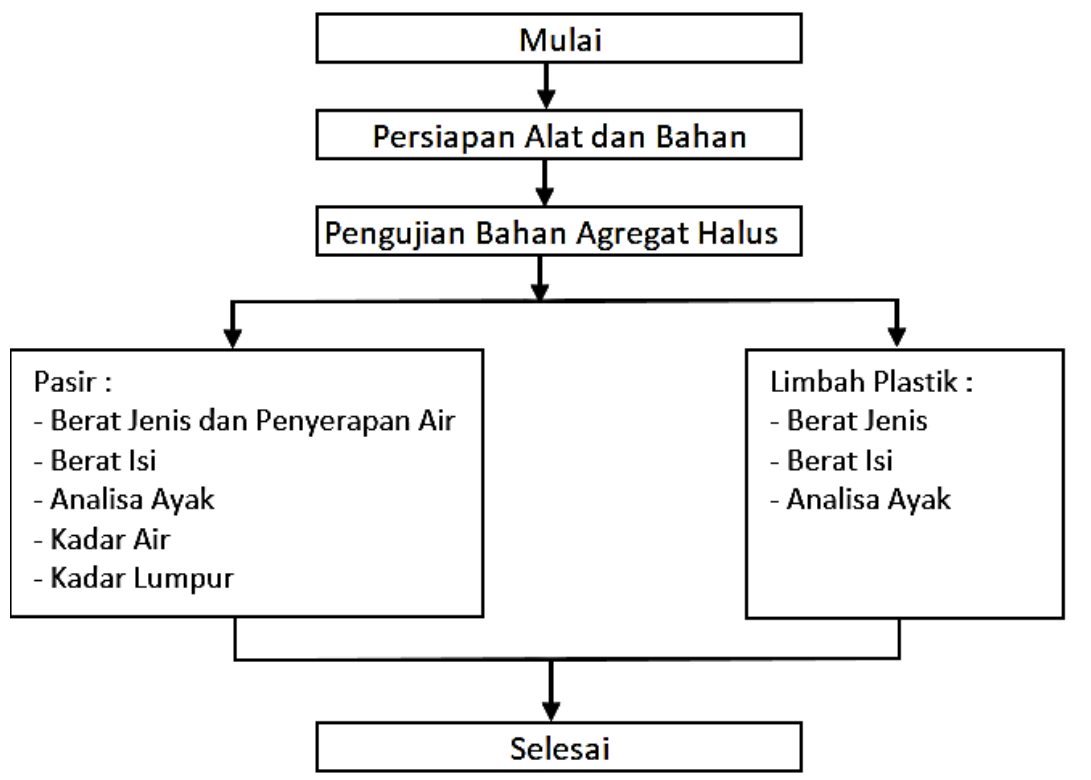

Gambar 4. Diagram Alir Pengujian Bahan Agregat Halus

Tabel 1. Agregat Halus Pasir dan Agregat Limbah Plastik

\begin{tabular}{lccc}
\hline \multirow{2}{*}{ Pengujian } & \multicolumn{2}{c}{ Agregat Halus } & \multirow{2}{*}{ Satuan } \\
\cline { 2 - 3 } & Pasir & Limbah Plastik & \\
\hline Berat Jenis SSD & 2,55 & 0,89 & $\%$ \\
$\begin{array}{l}\text { Penyerapan Air } \\
\text { Berat Isi }\end{array}$ & 2,35 & 0,00 & $\mathrm{Kg} / \mathrm{Liter}$ \\
• Lepas & 1,33 & 0,46 & $\mathrm{Kg} / \mathrm{Liter}$ \\
• Padat & 1,56 & 0,55 & \\
Voids & & & $\%$ \\
• Lepas & 35,54 & 48,450 & $\%$ \\
Analisa Ayak & 24,23 & 38,770 & $\%$ \\
Kadar Air & 2,90 & 4,15 & $\%$ \\
Kadar Lumpur & 1,93 & - & \\
\hline
\end{tabular}

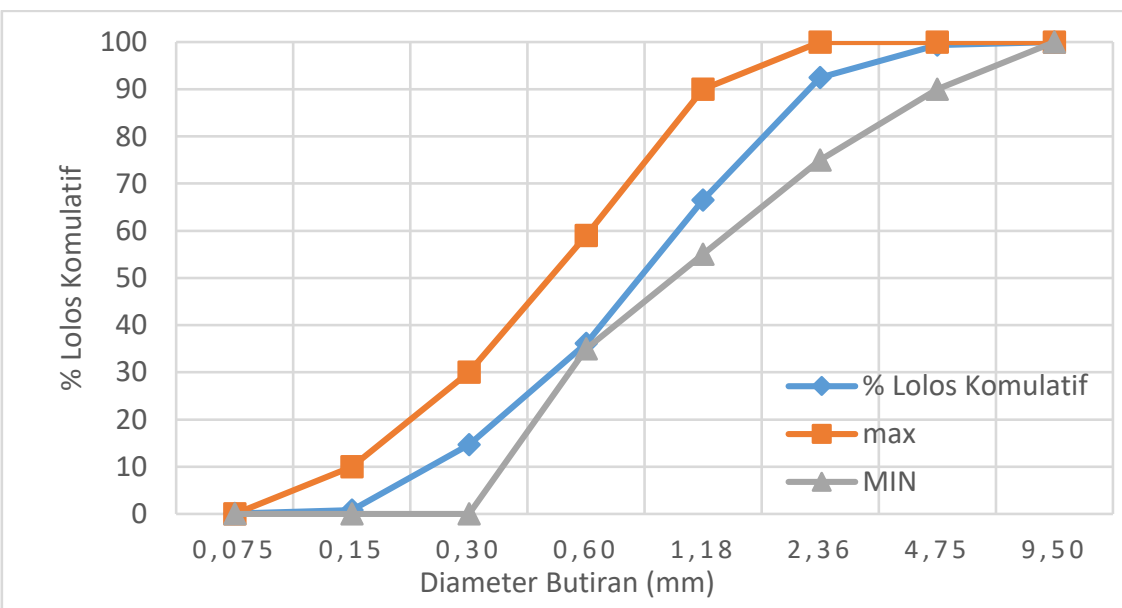

Gambar 5. Analisa Ayakan Agregat Halus 


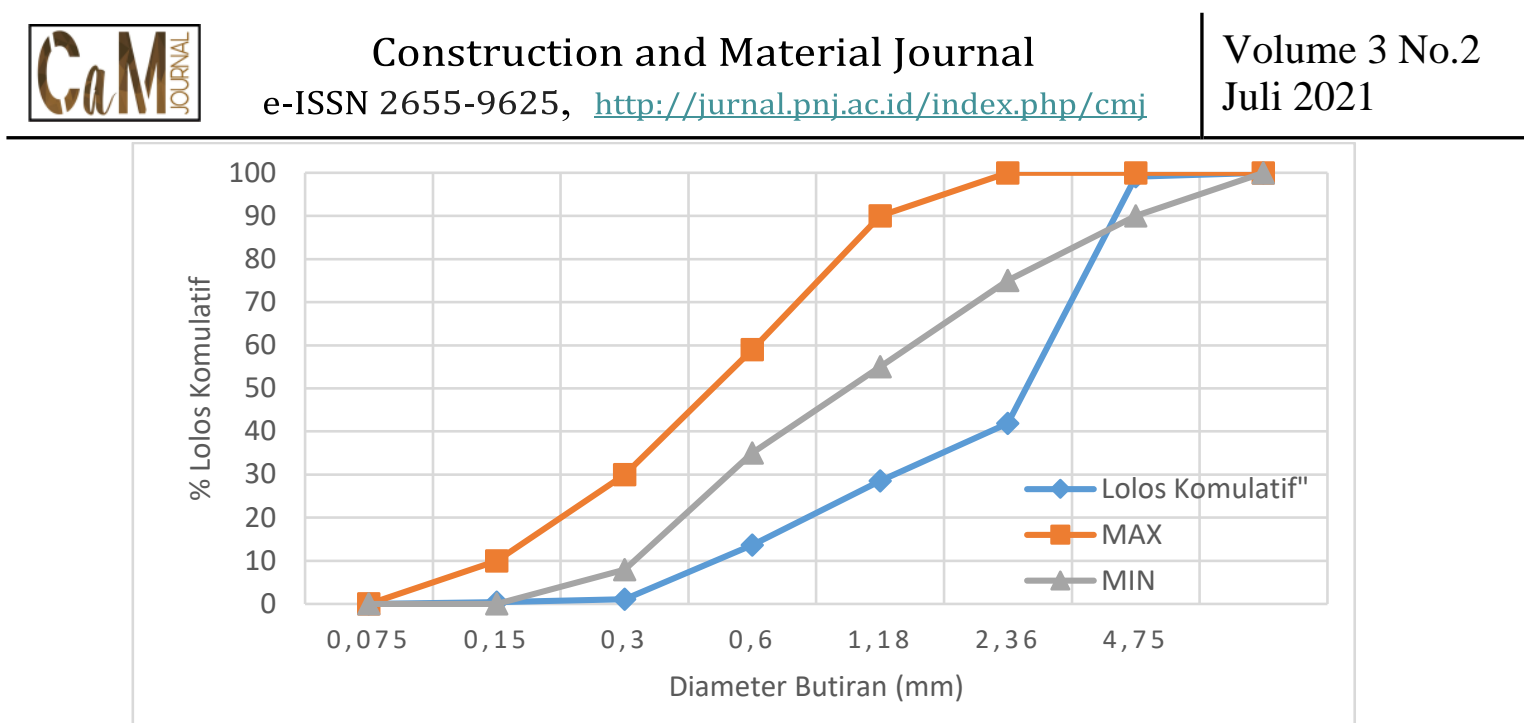

Gambar 6. Analisa Ayakan Agregat Halus Limbah Plastik 